\title{
A LOCKING HOOK-SPINAL ROD: CURRENT STATUS OF DEVELOPMENT*
}

\author{
By R. R. Jacobs, M.D., ${ }^{1}$ L. E. Dahners, M.D., ${ }^{1}$ S. D. Gertzbein, \\ M.D., ${ }^{2}$ A. Nordwall, M.D., ${ }^{3}$ and R. Mathys, JR ${ }^{4}$ \\ ${ }^{1}$ Orthopedic Section, Kansas University Medical Center, 39th and Rainbow Blvd., \\ Kansas City, KS 66I03. ${ }^{2}$ Sunnybrook Medical Centre, 2075 Bayview Ave., Toronto, \\ Ontario M4N 3M5. ${ }^{3}$ Sahlgren Hospital, Gothenburg, Sweden, S-4I3 45. ${ }^{4}$ Robert \\ Mathys Co., Bettlach, Switzerland.
}

Summary. A locking hook spinal rod previously demonstrated to be sufficiently stable and strong in cadaver experiments has been employed in 30 unstable thoraco-lumbar spinal injuries with results superior to Harrington instrumentation.

Key words: Thoraco-lumbar spinal injuries; Locking-hook spinal rod; Internal operative fixation.

\section{Introduction}

THREE deficiencies of Harrington distraction rods when used for fractures of the thoraco-lumbar spine are: the undesirable distraction force applied to the injured spine essential for attachment of the device to the spine, control of the lordotically contoured rod essential for three point bending, and the weakness of the rod when subjected to flexion bending loads. A biomechanical evaluation of available internal fixation devices demonstrated that isolated posterior ligamentous injuries were best stabilised with Harrington compression systems on the laminae and isolated anterior bony injuries with the Harrington distraction system. Combined anterior and posterior injuries stabilised with distraction rods had only half the strength of the isolated injuries (Jacobs, I980).

\section{Design}

A new system employing hooks which lock to the rod preventing rotation and by use of a sliding cover prevent escape of the lamina from the hook has been previously reported (Jacobs, 1980). Mechanical testing of this rod compared with the Harrington system demonstrated a 50 per cent increase in four point bending yield point, a 50 per cent increase in upper hook pullout strength, and a threefold increase in flexion bending strength of lumbar cadaver spinal injuries when stressed in four point flexion bending. A multicentre international clinical evaluation has been initiated.

\section{Clinical Material}

Thirty patients with unstable thoraco-lumbar spinal injuries have been

$\star$ Read at the Annual Scientific Meeting of the International Medical Society of Paraplegia, Athens, Greece. October 1982.

Supported by grants from AO-International, Berne, Switzerland and Asker's Foundation, Gothenburg, Sweden. 
treated with this device at three centres: 26 with the distraction system, two with the compression system, and two with offset sacral hooks. The Frankel classification of the initial neurologic involvement was: A-7 cases, $\mathrm{B}-3, \mathrm{C}-3, \mathrm{D}-5$ and $\mathrm{E}-\mathrm{I} 2$. The injuries were located from $\mathrm{T}_{5}$ to $\mathrm{L}_{4}$ with two-thirds between TIO and L2. At operation, the rod is first contoured to the anatomical shape of the posterior spine by studying the operative lateral X-ray. The device is inserted completely assembled, the lower hook first through a small interlaminar opening and fracture reduction completed (Fig. I). The plane of the contoured rod is fixed by locking the lower hook. The reduction is completed and the upper hook slid along the rod

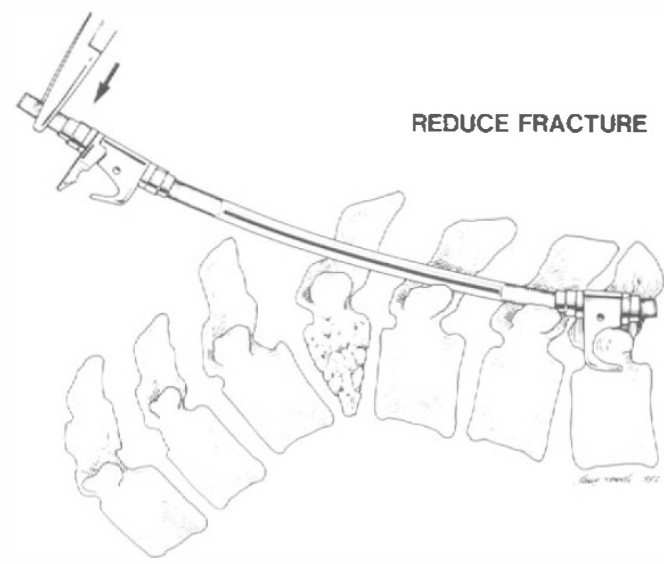

FIG. I

The lower hook is inserted first through a small interlaminar opening and the fracture reduction completed by pressing the upper end of the previously contoured rod downward.

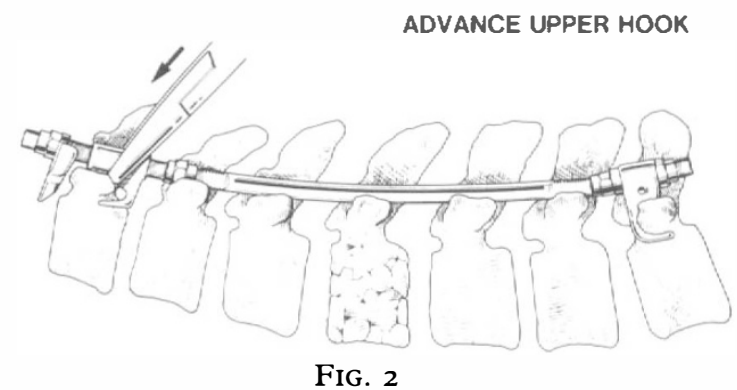

Using the hook holder the upper hook is first directed downward and then superiorly under the upper lamina.

and under the upper lamina (Fig. 2). The sliding cover is advanced over the lamina locking it in place (Fig. 3). The upper hook is fixed in position and all the nuts secured to the rod by crimping a locking collar (Fig. 4).

By modifying the physical therapy programme to avoid excessive flexion bending loads, paraplegic patients have not required additional orthotic support. Depending on patient reliaibility, temporary plaster or orthotic support has been used in ambulatory patients. 


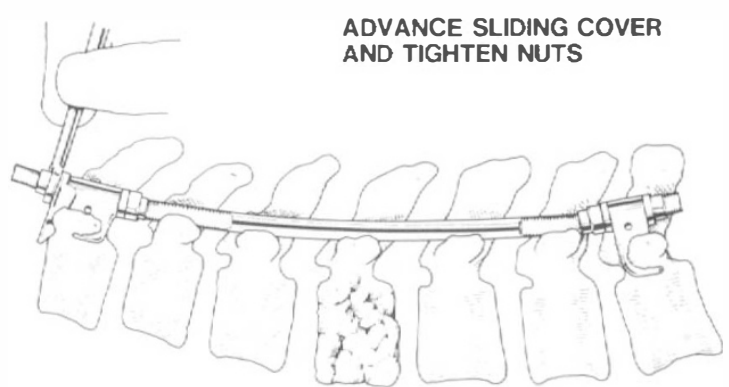

FIG. 3

The sliding cover is advanced over the top of the upper lamina locking it in place and all the nuts are tightened securely.

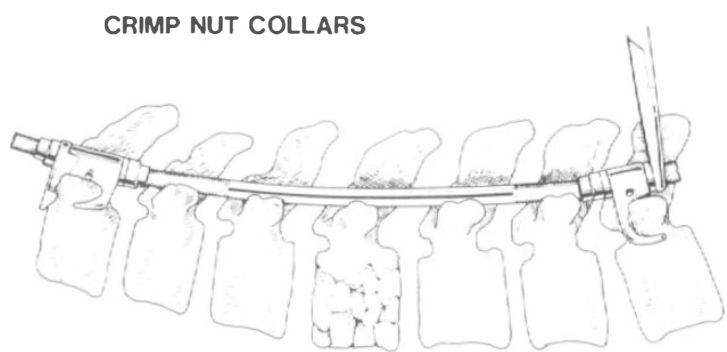

Fig. 4

All the nuts are secured to the rod by crimping the locking collar.

No neurological injuries have occurred intraoperatively nor has there been deterioration postoperatively. Eight of ten patients with partial deficit showed improvement of at least one Frankel level. There have been no mechanical failures, loss of fixation or reduction. With this system the rod long - fuse short approach has been used and 12 sets of implants have been removed for analysis at 9 months. No significant corrosion or evidence of metal fatigue has been found. Spinal flexibility has returned but the fused short segment has remained stable.

\section{Experimental Data}

Attachment of a fixation device to the caudal spinal segment remains a problem for lower lumbar spinal injuries. With only a single point of attachment to the pelvis three point fixation cannot be obtained. Using seven cadaver pelves, four techniques of pelvic fixation were tested:

I. Roy-Camille plates.

2. Harrington sacral bar.

3. Sacral bar reinforced with four hole plates over the posterior iliac crest.

4. The Luque rod with the Allen transverse iliac insertion.

The fixations were loaded in flexion bending with the application of 
loads $7 \mathrm{~cm}$ above the ala of the sacrum. The flexion bending loads $(\mathrm{Nm})$ at failure were respectively:

I. $14.7 \pm 2 \cdot 7$.

2. $33 \cdot 1 \pm 6 \cdot 7$.

3. $76 \cdot 8 \pm 13 \cdot 9$.

4. $8 \mathrm{I} \cdot 6 \pm \mathrm{I} 6 \cdot 8$.

By the Mann-Whitney rank test each result was significantly higher than the previous with $\mathrm{P}<0.05$ except for numbers 3 and 4 . Based on these data, a reinforced 'sacral bar' system has been developed which allows three point fixation for $\mathrm{L}_{5}$ injuries and does not require distraction.

\section{Conclusions}

Our clinical results compare favourably with the published 6 per cent rod breakage and 6 per cent loss of fixation rates with the Harrington system (Dickson, 1978). An expanded trial is now underway.

\section{RÉSUMÉ}

Une nouvelle méthode de stabilisation vertébrale après un traumatisme dorso-lombaire est décrite.

Il s'agit de l'utilisation de tiges avec accrochage et verrouillage sur les lames.

Elle a été utilisée chez 30 patients après essais sur le cadavre.

\section{ZUSAMMENFASSUNG}

In vorangegangenen Leichenversuchen wurde die Verwendbarkeit eines Stabes zur Fusion der Wirbelsäule untersucht. Er erwies sich als stabil und wurde bei instabilen Wirbelbrüchen am thorako-lumbalen Übergang bei 30 Patienten eingesetzt. Die Ergebnisse zeigen, daß das System dem HARRINGTON-Instrumentarium gegenüber überlegen ist.

\section{REFERENCES}

JACOBS, R. R., NoRdwall, A. \& NACHEMSON, A. (I980). Stability and strength provided by internal fixation systems for dorso-lumbar spinal injuries. Orthopedic Transactions: Orthopedic Research Society, 4, 229.

Jacobs, R. R., Schlaepfer, F., Mathys, R. JR. \& Perren, S. M. (I980). An experimental implant system for traumatic instability of the dorso-lumbar spine. Fournal of BioMechanics, I3, 80I.

Dickson, J. H., Harrington, P. R. \& Erwin, W. D. (1978). Results of reduction and stabilization of the severely fractured thoracic and lumbar spine. Fournal of Bone and foint Surgery, 60A, 799-805. 